\title{
Transfusion of older red blood cells increase the risk of postoperative infectious complications in pediatric scoliosis surgery: a propensity score matched analysis
}

\section{Lipeng Wang}

First Affiliated Hospital of Wannan Medical College

Jiangli Liu

First Affiliated Hospital of Wannan Medical College

Shuaishuai Chu

Nanjing Drum Tower Hospital

Ying Cui

Nanjing Drum Tower Hospital

Zhengliang Ma

Nanjing Drum Tower Hospital

Tianjiao Xia

Nanjing University

Xiaoping Gu

Nanjing Drum Tower Hospital

Yongquan Chen ( $\nabla$ chenyq263@163.com )

First Affiliated Hospital of Wannan Medical College

\section{Research Article}

Keywords: blood transfusion, pediatric scoliosis surgery, length of stay, postoperative complications

Posted Date: February 25th, 2022

DOI: https://doi.org/10.21203/rs.3.rs-1383510/v1

License: (9) This work is licensed under a Creative Commons Attribution 4.0 International License. Read Full License 


\section{Abstract}

Purpose: Pediatric scoliosis patients undergoing posterior spinal fusion surgery often need RBCs transfusion. However, the effects of storage time of transfused blood on perioperative outcomes remain undefined.

Methods: A retrospective study including 539 pediatric patients undergoing posterior spinal fusion surgery was conducted. These patients were divided into 2 groups: the fresh group, who received exclusively blood cells stored for 14 days or less; the older group, who received exclusively blood for more than 14 days. The effect of red blood cell storage time on length of hospital stay and postoperative complications was analyed by propensity score matching.

Results: The propensity score matching yielded 78 well-matched pairs after adjusting for potential confounders in baseline characteristics. Patients who received older blood had not prolonged length of stay compared with those received fresh blood (13.0 \pm 3.8 days vs $11.8 \pm 2.6$ days, $p=0.09)$. However, multivariable logistic regression analysis showed that older group had a higher incidence of infectious complications compared with fresh group $(\mathrm{OR}=2.15[95 \% \mathrm{Cl}, 1.08-4.31] ; \mathrm{P}=0.029)$.

Conclusions: In pediatric scoliosis patients undergoing posterior spinal fusion surgery, transfusion of older RBCs had a higher incidence of postoperative infectious complications but was not associated with prolonged length of hospital stay.

\section{Introduction}

Pediatric scoliosis surgery is technically challenging for both surgeons and anesthesiologists due to the complexity of procedures and the high risk for intraoperative massive blood transfusion[1]. However, blood transfusion was reported to be associated with increased morbidity, transfusion-related acute lung injury, infection, prolonged hospital duration of stay, and a higher risk for mortality[2]. Although the underlying mechanism of adverse event associated with blood transfusion is still unclear, one factor that may affect morbidity following blood transfusion is the progressive structural and function changes of red blood cells during longer storage time[3], which known as the "storage lesion". In addition, previous studies have suggested RBCs stored for longer time may have adverse effect on delivery oxygen and microcirculation $[4,5]$.

In china, RBCs for transfusion usage can be stored for a maximum of 35 days for manufacturing process. Long-term storage blood units are usually provided preferentially to minimize waste of blood components. Clinical evidence of the effect of RBCs storage duration on postoperative outcomes remains controversial. A number of retrospective studies have shown that transfusion of long-term stored blood were related to adverse consequences[2, 6, 7], while recent large randomized controlled trials found no difference in morbidity or mortality between fresh blood and older blood[8, 9]. In addition, some scholars believe volume-dependent effect of stored red blood cells was also correlated to clinical outcome. We speculate that the apparent contradiction in morbidity and mortality between analyses of randomized 
controlled trials and retrospective studies may in part relate to different ages of stored RBCs studied. The pediatric scoliosis patients undergoing posterior fusion surgery often often given large amounts of blood products. However, the effect of the storage duration of transfused RBCs on outcomes of pediatric scoliosis patients remains largely unknown. This study was conducted to determine the association between age of blood and length of hospital stay as well as postoperative complications in pediatric patients undergoing posterior spinal fusion surgery, in which massive blood transfusion was often required.

\section{Methods}

\section{1 patient populations}

Institutional review board approval was waived as patients' private information was not retrieved. This study investigated 539 scoliosis surgery patients in our hospital from January 2016 to December 2018. Pediatric scoliosis patients (11 to 18 years old) undergoing posterior spinal fusion surgery who had allogenic blood transfusion were included in this trial. Patients were excluded if they had revision operation ( $n=12)$, growing instrumentation extension $(n=16)$, previous blood cell transfusion $(n=4)$ during the current hospitalized, severe renal dysfunction $(n=2)$, or uncompleted medical data $(n=9)$. Patients who received both fresh and older blood were also excluded to reduce the effects of confounding factors $(n=80)$. Patients included were divided into 2 groups according to the storage time of transfused blood: patients received exclusively blood cells stored for 14 days or less (fresh group), and those received exclusively blood for more than 14 days (older group). A total of 416 patients were included in the current trial (Fig. 1). We chose 14th day as the cut-off point according to the previous study which claimed the risk of postoperative complications significantly increased after transfusion of blood stored for more than 14 days among patients undergoing intracardiac surgery[4]. The primary outcome was length of stay (defined as the number of days spent in hospital from the day of the operation to the day of discharge); the secondary outcome were postoperative complications, including infectious complications, pulmonary complications, postoperative hypoproteinemia and composite complications. Blood transfusion during perioperative period followed 2012 Blood Transfusion Guideline from The American Association of Blood Banks. Briefly, patients were given blood transfusion when hemoglobin level was below $70 \mathrm{~g} / \mathrm{dL}$, or below $80 \mathrm{~g} / \mathrm{dL}$ with massive bleeding. Hemoglobin level was maintained between $70 \mathrm{~g} / \mathrm{dL}$ and basal level after blood transfusion. Patients' baseline characteristic, intraoperative transfusion date, perioperative variables were retrieved from an anesthesia information management database system (Docare Medical System, Suzhou). Information of pre- and postoperative variables, postoperative complications, and laboratory date stored on Xianlian database system were collected by clinicians and match with the anesthesia database system. We accessed the hospital blood bank database registry to determine the storage time, volume of the blood transfusion and their $A B O$ blood type.

\subsection{Statistical analysis}


IBM SPSS 22.0 statistics software (SPSS, Inc, Chicago, IL) was used for all descriptive and comparative statistics. Continuous date were presented as mean \pm SD if distributed normally or as median (25th,75th) percentiles if not. Continuous variables were analyzed using independent 2-sample t-test or Mann-Whitey $\mathrm{U}$ test when needed, decided by the date distribution characteristics. Categorical data was compared using the Pearson chiquare test. To account for the nonrandom assignment of covariables among patients between the 2 cohorts, a propensity score matching analysis was employed. In this study, the following covariables were included: age, sex, body mass index, preoperative cobb angles, operative specific surgeons, American society of Anesthesiologists scores, estimated blood loss, duration of operation, types of scoliosis, number of fused levels and osteotomy. The description of propensity score matching in its application domain are published elsewhere[10,11]. In brief, we derive the propensity score through a nonparsimonious logistic model. The matching algorithm was 1:1 and nearest neighbor matching was no replacement. This means that each fresh case was matched to unique old case on the basis of nearest scores. If the differences in the propensity scores exceeded caliper width, the next fresh case would be tested until the matching was found. The optimal caliper width was equal to 0.2 times the standard deviation of the logit of the propensity score[12]. Multivivariate logistic regression analysis was used to assess the effect of the transfused blood cells age on postoperative infectious complications, pulmonary complications and postoperative hypoproteinemia, while adjusting for possible confounding variables, including patients age, sex, body mass index, preoperative cobb angles, estimated blood loss, duration of operation, number of fused levels and osteotomy.

\section{Results}

\subsection{Demographic and clinical characteristics}

From January 2016 to December 2018, a total of 539 pediatric scoliosis patients underwent posterior spinal fusion surgery, while 416 patients were analyzed according to the inclusion criteria Among these, $162(38.9 \%)$ patients received RBCs stored for 14 days or less (fresh blood) whereas $254(61.1 \%)$ patients received RBCs stored for more than 14 days (older blood). The most common types of scoliosis were idiopathic scoliosis $(n=195,46.8 \%)$ and congenital scoliosis $(n=115,27.6 \%)$. The baseline characteristics and surgical information of both groups were outlined in Table 1. Patients transfused fresh RBCs had larger preoperative Cobb angles compared with patients given older RBCs $(p=0.029)$. Of all patients included, females ( $n=289,69.4 \%)$ obviously outnumbered males $(n=127,30.6 \%)$ in the transfused cohort. In addition, the sexual proportion for transfused patients was different between two groups $(p=0.049)$. 
Table 1

demographic and clinical characteristics

\begin{tabular}{|c|c|c|c|}
\hline variable & $\begin{array}{l}\text { Fresh blood } \\
(n=162)\end{array}$ & $\begin{array}{l}\text { Older blood } \\
(n=254)\end{array}$ & p \\
\hline Age, years & $14.4 \pm 2.4$ & $14.5 \pm 2.9$ & 0.759 \\
\hline Gender (F/M) & $122 / 40$ & $167 / 87$ & 0.049 \\
\hline $\mathrm{BMI}, \mathrm{kg} / \mathrm{m}^{2}$ & $17.6 \pm 3.5$ & $19.1 \pm 3.7$ & 0.027 \\
\hline ASA, \% & & & 0.406 \\
\hline प & $136(84.0 \%)$ & $210(82.7 \%)$ & \\
\hline ૧ & $25(15.45 \%)$ & $44(17.3 \%)$ & \\
\hline ૧ & $1(0.6 \%)$ & 0 & \\
\hline Preoperative Cobb angle & $65.0 \pm 24.9$ & $59.7 \pm 23.6$ & 0.029 \\
\hline $\mathrm{Hb}, \mathrm{g} / \mathrm{dL}$ & $12.7 \pm 0.9$ & $12.8 \pm 1.0$ & 0.566 \\
\hline Intraoperative EBL, ml & $1079.2 \pm 650.2$ & $1057.2 \pm 667.3$ & 0.745 \\
\hline Duration of operation, min & $253.1 \pm 84.7$ & $280.5 \pm 84.3$ & 0.037 \\
\hline Operation type, n (\%) & & & 0.149 \\
\hline idiopathic scoliosis & $82(50.6 \%)$ & $113(44.5 \%)$ & \\
\hline Congenital scoliosis & $37(22.8 \%)$ & $78(30.7 \%)$ & \\
\hline neuromuscular scoliosis & $19(11.7 \%)$ & $37(14.6 \%)$ & \\
\hline other scoliosis & $24(14.8 \%)$ & $26(10.2 \%)$ & \\
\hline Number of fused levels & $10.3 \pm 2.9$ & $10.2 \pm 3.0$ & 0.790 \\
\hline Implant density, \% & $74.7 \pm 15.0$ & $73.1 \pm 14.1$ & 0.294 \\
\hline Osteotomy & $68(42 \%)$ & $133(52.4 \%)$ & 0.044 \\
\hline Surgeon & & & 0.428 \\
\hline A & $7(4.3 \%)$ & $5(2.0 \%)$ & \\
\hline B & $61(37.7 \%)$ & $92(36.2 \%)$ & \\
\hline C & $24(14.8 \%)$ & $52(20.5 \%)$ & \\
\hline D & $24(14.8 \%)$ & $34(13.4 \%)$ & \\
\hline$E$ & $46(28.4 \%)$ & $71(28.0 \%)$ & \\
\hline Unites of RBC transfused & $3.8 \pm 2.3$ & $3.9 \pm 2.6$ & 0.803 \\
\hline
\end{tabular}




\begin{tabular}{|llll|}
\hline variable & $\begin{array}{l}\text { Fresh blood } \\
(\mathbf{n = 1 6 2 )}\end{array}$ & $\begin{array}{l}\text { Older blood } \\
(\mathbf{n = 2 5 4 )}\end{array}$ & $\mathbf{p}$ \\
\hline Age of transfused RBC, days & $9.4 \pm 3.1$ & $21.1 \pm 3.9$ & $<0.001$ \\
\hline Other Blood products use, $\mathrm{n}(\%)$ & & & 0.808 \\
\hline Plasma & $46(28.0 \%)$ & $73(28.7 \%)$ & 0.878 \\
\hline Platelet & $2(1.2 \%)$ & $3(1.2 \%)$ & 0.961 \\
\hline Cryoprecipition & $6(3.7 \%)$ & $9(3.7 \%)$ & 0.994 \\
\hline
\end{tabular}

A total of 1615 units of RBCs were employed in the current study (Fig. 2), the average storage time was $16.5 \pm 6.7$ days. 162 patients received 620 RBCs units stored for 14 days or less, whereas 254 patients received a total of $995 \mathrm{RBC}$ units stored for more than 14 days. It is noteworthy that 82 patients receiving both fresh blood and older blood were not included in our analysis. The average storage time of the transfused blood was $9.4 \pm 3.1$ days in fresh group, compared with $21.1 \pm 3.9$ days in older group $(p<$ $0.001)$. The proportions of patients who received other blood products (plasma, platelets, and cryoprecipitate) were similar in both groups $(p=0.808)$.

\subsection{Propensity score-matched patient population}

A multivariate logistic regression model was created to derive the propensity scores for all patients, in which one fresh case was matched to the unique older case on the basis of the nearest propensity scores. 79 pairs of well-matched patients were yielded according to the matching algorithm (Table 2). The caliper width used for the matching procedure was 0.2 . After propensity score matching, the patient characteristics were well balanced between the two groups. 
Table 2

demographic characteristics and operative factors of patients after propensity score matching

\begin{tabular}{|c|c|c|c|}
\hline variable & $\begin{array}{l}\text { Fresh blood } \\
(n=79)\end{array}$ & $\begin{array}{l}\text { Older blood } \\
(n=79)\end{array}$ & $\mathrm{p}$ \\
\hline Age, years & $14.2 \pm 2.2$ & $14.6 \pm 2.9$ & 0.448 \\
\hline Gender (F/M) & $55 / 24$ & $47 / 32$ & 0.183 \\
\hline $\mathrm{BMl}, \mathrm{kg} / \mathrm{m}^{2}$ & $18.8 \pm 3.6$ & $18.7 \pm 3.7$ & 0.825 \\
\hline ASA, $\%$ & & & 0.087 \\
\hline प & 73 & 66 & \\
\hline प & 6 & 13 & \\
\hline प & 0 & 0 & \\
\hline Preoperative Cobb angle & $57.3 \pm 19.4$ & $58.3 \pm 21.4$ & 0.765 \\
\hline $\mathrm{Hb}, \mathrm{g} / \mathrm{dL}$ & $12.8 \pm 0.9$ & $12.9 \pm 0.9$ & 0.683 \\
\hline Intraoperative EBL, ml & $1024.7 \pm 531.5$ & $1100.2 \pm 730.9$ & 0.460 \\
\hline Duration of operation, min & $268.3 \pm 60.1$ & $280.5 \pm 74.5$ & 0.259 \\
\hline Operation type, n (\%) & & & 0.090 \\
\hline idiopathic scoliosis & $44(55.7 \%)$ & $38(48.1 \%)$ & \\
\hline Congenital scoliosis & $17(21.5 \%)$ & $22(27.8 \%)$ & \\
\hline neuromuscular scoliosis & $10(12.7 \%)$ & $17(21.5 \%)$ & \\
\hline other scoliosis & $8(10.1 \%)$ & $2(2.5 \%)$ & \\
\hline Number of fused levels & $10.7 \pm 2.5$ & $10.3 \pm 3.1$ & 0.372 \\
\hline Implant density, \% & $72.9 \pm 11.4$ & $73.2 \pm 11.9$ & 0.851 \\
\hline Osteotomy & $30(38.0 \%)$ & $41(51.9 \%)$ & 0.079 \\
\hline Surgeon & & & 0.980 \\
\hline A & $2(2.5 \%)$ & $3(3.8 \%)$ & \\
\hline B & $30(38 \%)$ & $28(35.4 \%)$ & \\
\hline C & $14(17.7 \%)$ & $16(20.3 \%)$ & \\
\hline D & $10(12.7 \%)$ & $10(12.7 \%)$ & \\
\hline$E$ & $23(29.1 \%)$ & $22(27.8 \%)$ & \\
\hline
\end{tabular}




\begin{tabular}{|llll|}
\hline variable & $\begin{array}{l}\text { Fresh blood } \\
(\mathbf{n}=79)\end{array}$ & $\begin{array}{l}\text { Older blood } \\
(\mathbf{n}=79)\end{array}$ & $\mathbf{p}$ \\
\hline Unites of RBC transfused & $3.6 \pm 1.8$ & $3.8 \pm 1.6$ & 0.786 \\
\hline Age of transfused RBC, days & $10.0 \pm 3.0$ & $21.5 \pm 3.9$ & $<0.001$ \\
\hline Other Blood products use, $\mathrm{n}(\%)$ & & & \\
\hline Plasma & $21(26.6 \%)$ & $3(36.7 \%)$ & 0.171 \\
\hline Cryoprecipition & $3(3.8 \%)$ & $2(2.5 \%)$ & 0.649 \\
\hline
\end{tabular}

\subsection{Perioperative outcomes in propensity score matched patients}

Comparison of perioperative outcomes between fresh and older groups in both unadjusted and propensity score matched patients are presented respectively in Table 3. In univariate analysis, the length of stay in older group ( $13.0 \pm 3.8$ days) was longer than in fresh group (11.8 \pm 2.6 days) $(p=0.01)$. To further explore the association between storage time of transfused blood and length of stay, we performed one-to-one propensity score matched analysis. The results demonstrated that transfusion of older red blood cells had not prolonged length of stay compared with fresh red blood cells $(p=0.09)$. Incidence of overall complications and infectious complications were significantly different between two groups through propensity score matching $(p<0.05)$, while that of pulmonary complications $(p=0.155)$, composite complications $(p=0.348)$ and hypoproteinema $(p=0.468)$ were no statistically different.

Table 3 comparison of perioperative outcomes in unadjusted and propensity score-matched patients 


\begin{tabular}{|c|c|c|c|c|c|c|}
\hline & \multicolumn{3}{|c|}{ Unadjusted Population } & \multicolumn{3}{|c|}{ Propensity-Matched Population } \\
\hline & Fresh, n (\%) & Older, $\mathrm{n}(\%)$ & \multirow{2}{*}{$P$} & $\begin{array}{l}\text { Fresh, } \mathrm{n} \\
(\%)\end{array}$ & $\begin{array}{l}\text { Older, } \\
\mathrm{n}(\%)\end{array}$ & \multirow{2}{*}{$P$} \\
\hline & $\begin{array}{l}162 \\
(38.9 \%)\end{array}$ & $\begin{array}{l}254 \\
(61.1 \%)\end{array}$ & & $79(50 \%)$ & $79(50 \%)$ & \\
\hline Length of stay (days) & $11.9 \pm 3.2$ & $13.1 \pm 4.9$ & 0.001 & $11.8 \pm 2.6$ & $13.0 \pm 3.8$ & 0.09 \\
\hline Overall complications & $30(18.5 \%)$ & $69(27.2 \%)$ & 0.043 & $12(15.1 \%)$ & $\begin{array}{l}24 \\
(30.3 \%)\end{array}$ & 0.023 \\
\hline Infections complications & $15(9.3 \%)$ & $42(16.4 \%)$ & 0.038 & $6(7.5 \%)$ & $\begin{array}{l}15 \\
(18.8 \%)\end{array}$ & 0.035 \\
\hline $\begin{array}{l}\text { Pulmonary } \\
\text { complications }\end{array}$ & $2(1.2 \%)$ & $8(3.2 \%)$ & 0.037 & 0 & $2(2.5 \%)$ & 0.155 \\
\hline Hypoproteinema & $9(5.6 \%)$ & $15(5.9 \%)$ & 0.881 & $3(3.8 \%)$ & $5(6.3 \%)$ & 0.468 \\
\hline $\begin{array}{l}\text { Composite } \\
\text { complications }\end{array}$ & $10(6.2 \%)$ & $20(7.9 \%)$ & 0.513 & $4(5.1 \%)$ & $7(8.9 \%)$ & 0.348 \\
\hline
\end{tabular}

The effects of RBCs storage time on postoperative complications were evaluated by multivariable logistic analysis, in which potential confounding factors were considered. The results revealed that transfusion of older RBCs increased the risk of overall complications (OR, 1.79; $95 \% \mathrm{Cl}, 1.09-2.93 ; P=0.02)$ and postoperative infectious $(\mathrm{OR}, 2.15 ; 95 \% \mathrm{Cl}, 1.08-4.31 ; P=0.029)$, while that of pulmonary complications (OR, 4.81; 95\% Cl, 0.45-51.25; $P=0.192$ ), composite complications (OR, 1.52; 95\% $\mathrm{Cl}, 0.67-3.45 ; P=$ $0.316)$ and hypoproteinema $(\mathrm{OR}, 1.24 ; 95 \% \mathrm{Cl}, 0.51-3.04 ; P=0.626)$ were not significant different between groups(Table 4) 
Table 4

Multivivariate logistic regression analysis of postoperative complications

\begin{tabular}{|c|c|c|c|c|c|c|}
\hline \multirow[t]{2}{*}{ Outcomes } & \multirow{2}{*}{$\begin{array}{l}\text { Patients } \\
\text { Receiving Fresh } \\
\text { Blood } \\
(n=162)\end{array}$} & \multirow{2}{*}{$\begin{array}{l}\text { Patients } \\
\text { Receiving Older } \\
\text { Blood } \\
(n=254)\end{array}$} & \multicolumn{2}{|c|}{$\begin{array}{l}\text { Univariate } \\
\text { Analysis }\end{array}$} & \multicolumn{2}{|c|}{$\begin{array}{l}\text { Multivariable } \\
\text { Analysis }\end{array}$} \\
\hline & & & $P$ & $\begin{array}{l}\text { OR } \\
\text { (95\% Cl) }\end{array}$ & $P$ & $\begin{array}{l}\text { OR } \\
(95 \% \mathrm{Cl})\end{array}$ \\
\hline $\begin{array}{l}\text { Infectious } \\
\text { complications }\end{array}$ & 15 (9.3\%) & $42(16.4 \%)$ & 0.038 & $\begin{array}{l}1.92 \\
(1.03- \\
3.59)\end{array}$ & 0.029 & $\begin{array}{l}2.15 \\
(1.08- \\
4.31)\end{array}$ \\
\hline $\begin{array}{l}\text { Pulmonary } \\
\text { complications }\end{array}$ & $2(1.2 \%)$ & 8 (3.2\%) & 0.037 & $\begin{array}{l}2.03 \\
(1.09- \\
3.76)\end{array}$ & 0.192 & $\begin{array}{l}4.81 \\
(0.45- \\
51.25)\end{array}$ \\
\hline $\begin{array}{l}\text { Length of stay } \\
\text { (day) }\end{array}$ & $11.9 \pm 3.2$ & $13.1 \pm 4.9$ & 0.001 & & & \\
\hline
\end{tabular}

\section{Discussion}

The pediatric scoliosis patients undergoing posterior spinal fusion surgery frequently require a large number of blood transfusion due to the complexity of procedures. In the current study, we found that pediatric scoliosis patients who transfused older blood were 1.76 times more likely to develop postoperative infectious complications than those who transfused fresh blood. However, the transfusion of RBCs that stored for more than 14 days was not associated with prolonged length of stay.

Our results corroborate the findings of a series of retrospective trials that have shown increased adverse outcomes when transfusing older blood[8, 13, 14]. Jill et al also repoted that transfusion of RBCs stored for more than 25 days was associated with increased postoperative nosocomial infections compared to transfusion with fresher blood in pediatric cardiac surgery[15]. Notably, some large randomized control trials (RCTs) have not found adverse effect of blood age on clinical outcomes in pediatric patients[16], critically ill trauma patients[17], cardiac surgery patients[18]. This could be due to reason that the toxicity of the stored RBCs may be dose-dependent. According to the results of these prospective trials, a number of patients were transfused too few RBCs to perceive the effects of RBCs storage lesion. A significant proportion of patients were transfused only 1 or 2 units of RBCs, the number of transfused RBCs may not reach the threshold for storage lesion. Johnathan et al. [19] reported an increased risk of mortality in patients transfused stored RBCs after a threshold of 6 RBC units. Allison et al. also suggests that the effect of stored RBCs on 24-hour mortality is dose-dependent in trauma patients[20].

Pathways and mechanisms between longer storage times of transfused RBCs with adverse postoperative outcomes were complex. Several underlying factors may explain the effect of RBCs transfusion on clinical outcomes. Metabolic changes occur as a important cause for storage lesion development. Depletion of critical substrates (i.e., ATP and 2, 3-diphosphoglycerate) and accumulation of lactic acid impaired activities of critical enzymes and antioxidant defense[21]. The depletion of age-related 2, 3diphosphoglycerate (2, 3-DPG) led to inadequate oxygen supply to tissues by shifting the oxyhemoglobin 
dissociation curve to the left during the period of storage[21, 22]. Furthermore, progressive biochemical and structural changes in red blood cells during storage have also been considered to be an important mechanism. Frank et al[23] indicated that longer storage time of transfused RBCs was associated with decreased cell membrane stability, which still last after transfusing into body. The scleroid cell membrane may block the the flow through small capillaries that are Same or smaller than erythrocytes itself in size. Therefore, RBC "storage lesion" may reduce the functionality of red blood cells and have significant clinical outcomes for patients[24-25].

In this study, we found that longer red blood cell storage time increased postoperative infectious in pediatric scoliosis patients. Our results were in accordance with the hemolysis-iron hypothesis that nontransferrin bound iron increased nosocomial infection after allogeneic transfusion[26]. During the storage of red blood cells, iron is released in such quantities that it exceeds the binding capacity of transferrin and circulates in the form of non-transferrin bound iron, which is associated with higher rates of infection[27]. There was no association between red blood cell storage time and length of stay. This may be because the length of stay is a comprehensive result of disease severity, therapeutic efficacy and safety, that is largely modulated by social factors. In addition, the toxicity of the stored RBCs could be dose-dependent, the number of transfused RBCs may not influence length of stay in current study.

The median storage time of transfused blood was 16 days in this study. In addition, research shows that the storage lesion becomes apparent when RBCs are stored for more than 14 days[28]. In this study, the patients were divided into 2 groups: fresh blood group that was transfused exclusively RBCs stored for 14 days or less and older blood group that was transfused RBCs stored for more than 14 days. In this study, the number of patients transfusing fresh blood is not equal to the number of patients transfusing older blood. The number of RBCs transfused is related to the adverse outcomes of blood transfusion. Therefore, the number of RBCs that the patient received in perioperative could be a important confounding factor. In view of the above, we applied propensity score matching to the clinical characteristics and perioperative parameters to reduce distortion by confounding factors.

There were also several limitations in this study. since this study is a retrospective study from a tertiary care center, it would be apt to cause bias. In the future, the further randomized controlled trial studies are still needed to confirm the effect of storage time of transfused blood on postoperative infection in scoliosis corrective surgery. In addition, the sample capacity was relatively small, which weakens the ability to adequately adjust for confounding variables.

In summary, we studied the effects of the storage time of transfused blood on perioperative outcomes in pediatric scoliosis patients. We found that transfusion of older RBCs had a higher incidence of postoperative infectious complications but was not associated with prolonged length of hospital stay.

\section{Abbreviations}

EBL: estimated blood loss; Hb: Hemoglobin; BMl: Body mass index; ASA: American society of Anesthesiologists; 


\section{Declarations}

Acknowledgements

None

Authors' contributions

All authors contributed to the study conception and design. Material preparation, data collection and analysis were performed by Jiangli Liu, Shuaishuai Chu and Cui Ying. The first draft of the manuscript was written by Lipeng Wang and all authors commented on previous versions of the manuscript. Xiaoping Gu and Yongquan Chen designed and supervised the entire study. All authors read and approved the final manuscript.

\section{Funding}

Funding for this study was provided by National Natural Science Foundation of China (81701371, 81801380), the Key Talent's 13th Five-Year Plan for Strengthening Health of Jiangsu Province of China (ZDRCA2016069), The National Key R\&D Program of China (GXP, grant numbers 2018YFC2001901).

Availability of data and materials

The datasets generated during and analyzed during the current study are not publicly available due to hospital regulations but are available from the corresponding author on reasonable request.

Ethics approval and consent to participate

No patients' private information is involved. The retrospective study was waived for the ethical approval and informed consent by the ethic committee of Affiliated Drum Tower Hospital, Medical School of Nanjing University. We confirm that all methods were carried out in accordance with relevant guidelines and regulations.

Consent for publication

Not applicable.

Competing interests

The authors declare that they have no competing interests from a commercial party related directly or indirectly to the subject of this article.

Author details

${ }^{1}$ Department of Anaesthesia, Yijishan Hospital of Wannan Medical College, No. 2, Zheshan West Road, Wuhu, Anhui, China. ${ }^{2}$ Department of Anesthesiology, Affiliated Drum Tower Hospital, Medical School of 
Nanjing University, Nanjing, China. ${ }^{3}$ Medical School, Nanjing University, Nanjing, China. ${ }^{4}$ Jiangsu Key Laboratory of Molecular Medicine, Nanjing University, Nanjing, China.

\section{References}

1. van Popta D, Stephenson J, Patel D, et al. The pattern of blood loss in adolescent idiopathic scoliosis. Spine J. 2014;14(12):2938-2945.

2. Koch CG, Li L, Sessler DI, et al. Duration of red-cell storage and complications after cardiac surgery. N Engl J Med 2008;358(12):1229-1239.

3. Koch CG, Figueroa PI, Li L, et al. Red blood cell storage: how long is too long? Ann Thorac Surg 2013;96(5):1894-1899.

4. Tanaka S, Harrois A, Duranteau J. Leukodepleted versus nonleukodepleted red blood cell transfusion in septic patients: a microcirculatory vision. Crit Care 2014(2);18:128.

5. Tsai AG, Hofmann A, Cabrales P, et al. Perfusion vs. oxygen delivery in transfusion with "fresh" and "old" red blood cells: the experimental evidence. Transfus Apher Sci 2010(1);43:69-78.

6. Kim Y, Amini N, Gani F, et al. Age of Transfused Blood Impacts Perioperative Outcomes Among Patients Who Undergo Major Gastrointestinal Surgery. Ann Surg 2017(1);265:103-110.

7. Ng MSY, David M, Middelburg RA, et al. Transfusion of packed red blood cells at the end of shelf life is associated with increased risk of mortality - a pooled patient data analysis of 16 observational trials. Haematologica. 2018;103(9):1542-1548.

8. Heddle NM, Cook RJ, Arnold DM, et al. Effect of Short-Term vs. Long-Term Blood Storage on Mortality after Transfusion. N Engl J Med 2016;375(20):1937-1945.

9. Cooper DJ, McQuilten ZK, Nichol A, et al. Age of red cells for transfusion and outcomes in critically ill adults. N Engl J Med. 2017;377(19):1858-1867.

10. Thoemmes FJ, Kim ES. A Systematic Review of Propensity Score Methods in the Social Sciences. Multivariate Behav Res 2011;46(1):90-118.

11. Stukel TA, Fisher ES, Wennberg DE, et al. Analysis of observational studies in the presence of treatment selection bias: effects of invasive cardiac management on AMI survival using propensity score and instrumental variable methods. JAMA 2007;297:278-285.

12. Austin PC. Optimal caliper widths for propensity-score matching when estimating differences in means and differences in proportions in observational studies. Pharm Stat 2011;10(2):150-161.

13. Jones AR, Patel RP, Marques MB, et al. Older blood is associated with increased mortality and adverse events in massively transfused trauma patients: Secondary analysis of the PROPPR trial. Ann Emerg Med. 2019;73(6):650-661.

14. Yue W, Qingshan L, Tao M, et al. Transfusion of Older Red Blood Cells Increases the Risk of Acute Kidney Injury After Orthotopic Liver Transplantation: A Propensity Score Analysis. Anesth Analg 2018;127(1):202-209. 
15. Cholette JM, Pietropaoli AP, Henrichs KF, et al. Longer RBC storage duration is associated with increased postoperative infections in pediatric cardiac surgery. Pediatr Crit Care Med. 2015;16(3):227-235.

16. Spinella Philip C, Marisa Tucci, Dean A, et al. Effect of Fresh vs Standard-issue Red Blood Cell Transfusions on Multiple Organ Dysfunction Syndrome in Critically III Pediatric Patients: A Randomized Clinical Trial. JAMA. 2019;322(22):2179-2190.

17. Robert $S$, Mete $E$, Jacques $L$, et al. Age of transfused blood in critically ill adult trauma patients: a prespecified nested analysis of the Age of Blood Evaluation randomized trial. Transfusion. 2018;58(8):1846-1854.

18. Steiner ME, Ness PM, Assmann SF, et al. Effects of red-cell storage duration on patients undergoing cardiac surgery. N Engl J Med. 2015;372(15):1419-1429.

19. Johnathan M, Susan R, Alan T, et al. Volume-dependent effect of stored red blood cells: A secondary analysis of the Age of Blood Evaluation trial. Transfusion. 2020;60:1929-1939.

20. Allison R, Rakesh P, Marisa B, et al. Older Blood Is Associated With Increased Mortality and Adverse Events in Massively Transfused Trauma Patients: Secondary Analysis of the PROPPR Trial. Ann Emerg Med. 2019;73(9):650-661.

21. Tatsuro Y, Michel P, Angelo D, et al. Red blood cell storage lesion: causes and potential clinical consequences. Blood Transfus. 2019;17(1):27-52

22. d'Almeida MS, Jagger J, Duggan M, et al. A comparison of biochemical and functional alterations of rat and human erythrocytes stored in CPDA-1 for 29 days: implications for animal models of transfusion. Transfus Med 2000;10(4):291-303.

23. Frank SM, Abazyan B, Ono M, et al. Decreased erythrocyte deformability after transfusion and the effects of erythrocyte storage duration. Anesth Analg 2013;116(5):975-981.

24. Koch Colleen G. et al. Effect of red blood cell storage duration on major postoperative complications in cardiac surgery: A randomized trial. The Journal of Thoracic and Cardiovascular Surgery 2020; 160(6): 1505-1514.

25. Marissa R, Chantal D, Tomas M, et al. Potential Consequences of the Red Blood Cell Storage Lesion on Cardiac Electrophysiology. Journal of the American Heart Association 2020; 9(21): e017748e017748.

26. Ozment CP, Turi JL, et al. Iron overload following red blood cell transfusion and its impact on disease severity. Biochim Biophys Acta. 2009; 1790(7):694-701.

27. Hod EA, Brittenham GM, Billote GB, et al. Transfusion of human volunteers with older, stored red blood cells produces extravascular hemolysis and circulating non-transferrin-bound iron. Blood. $2011 ; 118(25): 6675-6682$.

28. D'Alessandro A, Kriebardis AG, Rinalducci S, et al. An update on red blood cell storage lesions, as gleaned through biochemistry and omics technologies. Transfusion. 2015;55(1):205-219.

\section{Figures}


Pediatric scoliosis patients (11 to 18 years old) underwent posterior spinal fusion surgery from January 2016 to December 2018 ( $\mathrm{n}=539$ )

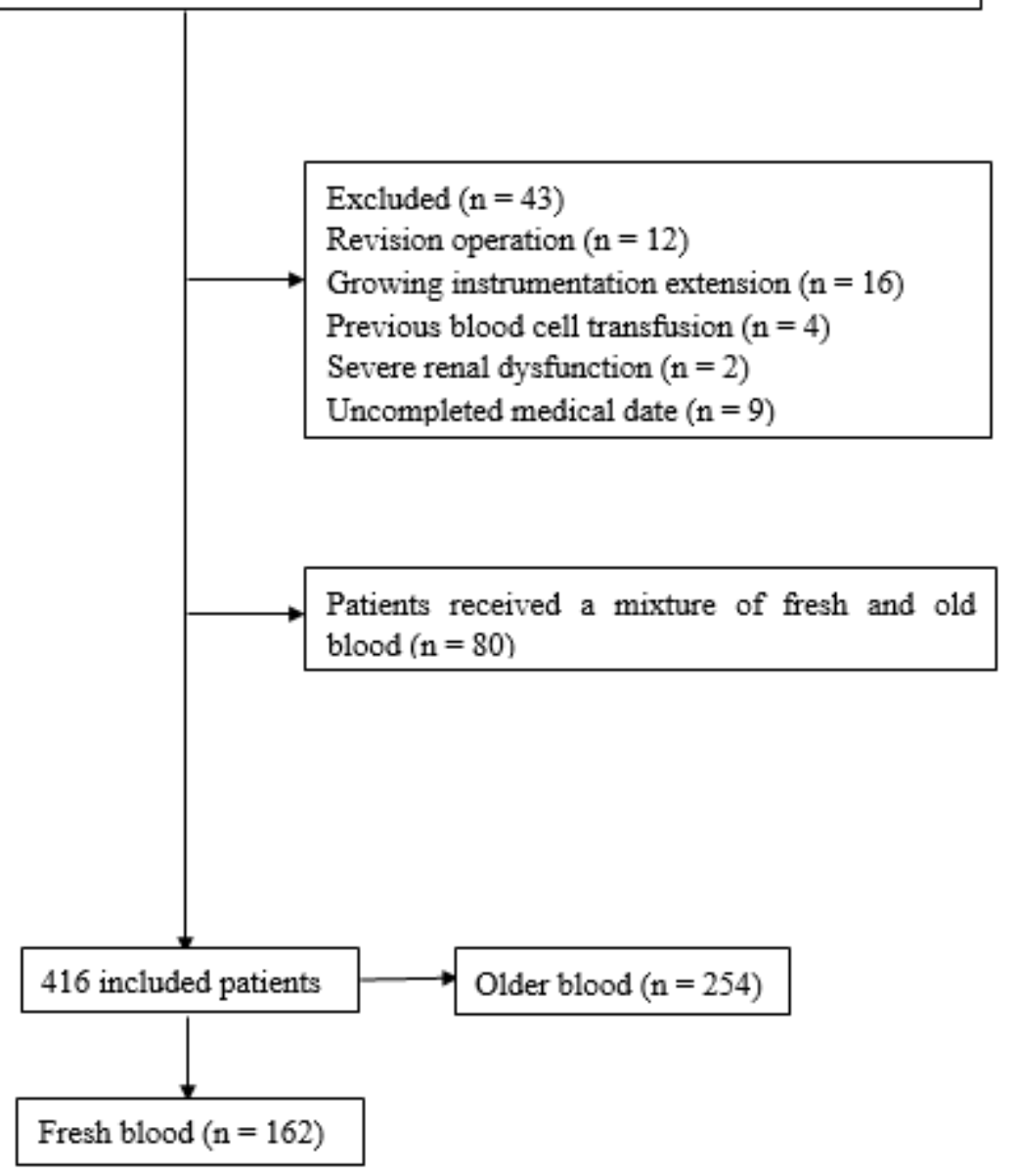

\section{Figure 1}

Patient screening diagram 


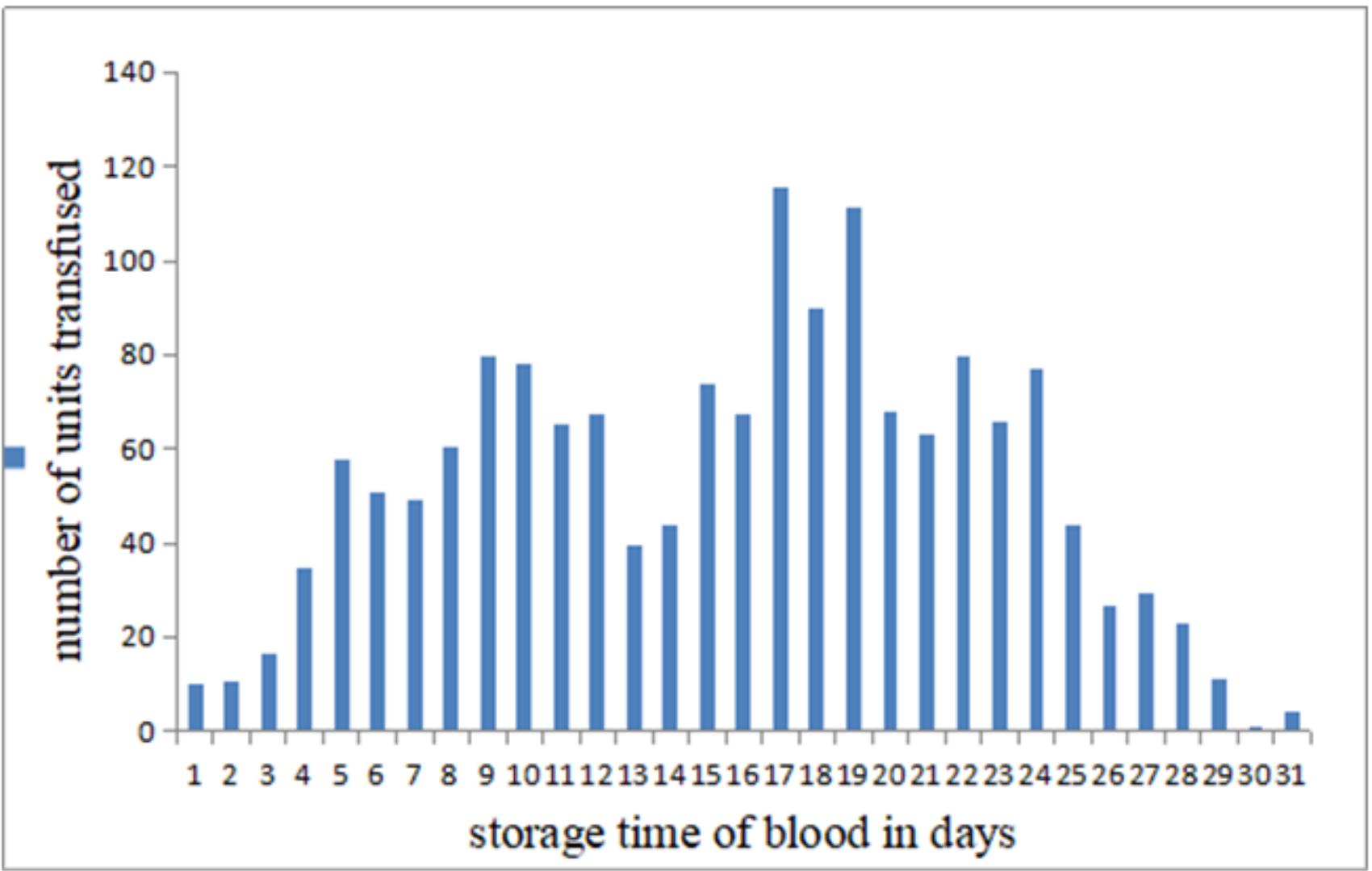

Figure 2

storage time of all transfused RBCs 